\title{
The Impact of Mergers and Acquisitions on the Profitability of Indian Pharmaceutical Industry
}

\author{
C. Dhanalakshmi* \\ Assistant Professor, Department of Commerce (AICM), Sri Krishna Arts and Science College, Coimbatore, Tamil Nadu, \\ India; dhanalakshmic@skasc.ac.in
}

\begin{abstract}
In today's globalized economy, the main objective of every firm is to make profits and enhance the shareholders' wealth. In the global market, a number of companies among Indian pharmaceuticals have entered into Merger and Acquisition agreements. The objective of the study is to evaluate the impact of Merger and Acquisition on the Profitability of select pharmaceutical companies. For the present study, 8 pharmaceutical companies listed under BSE which involved in M\&A activities in India after recession period i.e. after 2007 were chosen. The analysis is based on the various profitability ratios which are compared between pre and post-event periods. Other statistical tools- Mean, Standard Deviation, Co-efficient of Variation and Paired ' $\mathrm{t}$ ' test have been used in this research.
\end{abstract}

Keywords: Acquisition Agreements, Mergers and Acquisitions, Pharmaceuticals, Recession

\section{Introduction}

The Indian pharmaceutical companies have a wide variety of experience in manufacturing as per global standards. Due to intensive competition in the Indian market, Indian companies are experienced in the manufacturing of a variety of formulations that make them efficient and competitive in their operations. The Indian Pharmaceutical Industry is the $3^{\text {rd }}$ largest pharmaceutical market in terms of volume and $10^{\text {th }}$ largest in terms of value, contributing towards $10 \%$ of global production 1 The pharmaceutical Industry in India has remained on a strong growth trajectory, over the past few years, and is expected to increase to USD 48 billion by 2017-18 at a CAGR of 14\%? Mergers and Acquisitions (M\&A) are among the most effective ways to expedite the implementation of a plan to grow rapidly. The Indian Pharmaceutical Industry is witnessing increased M\&A activities from domestic and international players which will help to boost R\&D expenditure to achieve economies of scale and to strengthen the marketing network at a lightning speed. The impact of technology and the internet has further increased the pace and size of deals.

\section{Review of Literature}

Matthew J. Higgins and Daniel Rodriguez, (2005) ${ }^{3}$ identified the performance of 160 pharmaceutical acquisitions from 1994-2001 and found evidence that on an average, acquirers realized significant positive returns. Polina Grill and Rudi K. F. Bresser (2011) ${ }^{4}$ inferred in their study that M\&A were the most popular external growth strategy; the shareholders of target firms gained value during the acquisition process, while acquirers did not receive abnormal positive returns. Nadia Teixeira, (2012) $\underline{5}$ estimated the enterprise value of both companies (acquirer and acquired) as if they were optimally managed and assessed the value of the merged entity and the synergies created. Peng Cheng Zhu and Peter E. Hilsenrath, (2014) noted in case of large acquisitions in the retail pharmaceutical industry, that in spite of rapid growth, profitability eroded. They also showed that the concentration of the retail pharmaceutical industry was negatively correlated with producer prices and positively correlated with profitability. According to Neha Duggal, (2015)? M\&A were considered as a significant tool for corporate restructuring

*Author for correspondence 
and value creation in the present scenario. Samra Chaudary and Asif Sarwar, (2015)을 determined the shareholders' wealth of the acquirer U. S. pharmaceutical companies after M\&A. Santosh Kumar Sahu and Nitika Agarwal, (2015)弚observed that M\&A were common strategies of firms to increase the performance and also brought to the fore the factors affecting M\&A activities in the Indian pharmaceutical sector.

\section{Objective of the Study}

- To evaluate the impact of Mergers and Acquisitions on the profitability of the select Indian pharmaceutical companies.

\section{Methodology}

The present study is based on eight pharmaceutical companies listed under BSE which involved in M\&A activities in India after recession period i.e. after 2007. The basic criterion of this research is that the M\&A deals should have been exhibited after 2007 and Acquirer should have at least 5 financial years in both pre and post-merger periods. Out of 61 M\&A deals in India, 8 M\&A only occurred after 2007 and hence considered for the study. The annual reports of the select 8 companies were collected from the CMIE database and the respective company websites.
The period of study comprising five financial year before-merger and after-merger for the select 8 companies ranged between 2003-04 and 2015-16.

\section{Tools of Analysis}

- Profitability ratios were computed and compared between pre and post-merger periods.

- The statistical tools namely Mean, Standard Deviation, Co-efficient of Variation and Paired' 't' test were employed in this research.

\section{Impact on Profitability}

\subsection{Return on Total Assets}

The Return on Total Assets (ROTA) ratio measures a company's Earnings Before Interest and Taxes (EBIT) against its total net assets. Higher the ratio, better the company has effectively utilized its assets to earn profit. In order to determine the impact of M\&A on the return on total assets in respect of the select pharmaceutical companies the following null hypothesis was framed.

$\mathbf{H}_{\mathbf{0}}$ : There is no significant difference in the return on total assets ratio between before and after-merger periods in respect of the select companies.

Table 1: Return on Total Assets Ratio (In Times)

\begin{tabular}{|c|c|c|c|c|c|c|c|c|}
\hline Period & $\begin{array}{c}\text { SMS } \\
\text { Pharmaceuticals } \\
\text { Ltd. }\end{array}$ & $\begin{array}{c}\text { Strides } \\
\text { Shasun Ltd. }\end{array}$ & $\begin{array}{c}\text { Sequent } \\
\text { Scientific } \\
\text { Ltd. }\end{array}$ & $\begin{array}{c}\text { Sri Krishna } \\
\text { Pharmaceuticals } \\
\text { Ltd. }\end{array}$ & $\begin{array}{c}\text { Makers } \\
\text { Labs } \\
\text { Ltd. }\end{array}$ & $\begin{array}{l}\text { Abbott } \\
\text { India } \\
\text { Ltd. }\end{array}$ & $\begin{array}{c}\text { Aarti } \\
\text { Drugs } \\
\text { Ltd. }\end{array}$ & $\begin{array}{l}\text { IPCA } \\
\text { Labs. } \\
\text { Ltd. }\end{array}$ \\
\hline \multirow{5}{*}{ Before Merger } & 7.82 & 6.48 & 14.27 & 3.85 & 1.47 & 27.11 & 4.73 & 10.98 \\
\hline & 7.62 & 7.03 & 18.93 & 4.55 & 5.17 & 24.21 & 4.39 & 16.86 \\
\hline & 7.03 & 5.21 & 21.59 & 2.38 & -1.45 & 29.49 & 4.16 & 14.69 \\
\hline & 8.56 & -8.81 & 2.58 & 9.33 & 12.36 & 28.32 & 5.04 & 8.38 \\
\hline & 9.06 & 0.42 & 3.24 & 8.88 & 10.89 & 28.54 & 8.19 & 15.74 \\
\hline Mean & 8.017 & 2.064 & 12.121 & 5.799 & 5.688 & 27.535 & 5.300 & 13.330 \\
\hline SD & 0.797 & 6.616 & 8.812 & 3.122 & 5.928 & 2.041 & 1.649 & 3.541 \\
\hline CV (\%) & 9.945 & 320.56 & 72.703 & 53.842 & 104.205 & 7.413 & 31.107 & 26.569 \\
\hline \multirow{5}{*}{ After Merger } & 1.80 & 4.88 & 8.23 & 8.88 & 10.65 & 19.95 & 5.83 & 16.05 \\
\hline & 0.64 & 2.78 & 5.23 & 2.59 & -1.95 & 21.54 & 4.92 & 14.96 \\
\hline & 2.17 & 5.09 & 0.42 & 6.87 & 8.70 & 21.40 & 8.76 & 15.07 \\
\hline & 0.28 & 2.71 & -14.33 & 6.76 & 2.06 & 23.82 & 10.21 & 18.41 \\
\hline & 6.75 & 165.48 & -28.08 & 6.76 & 8.00 & 23.44 & 10.80 & 8.05 \\
\hline Mean & 2.329 & 36.189 & -5.707 & 6.372 & 5.491 & 22.031 & 8.102 & 14.507 \\
\hline SD & 2.592 & 72.285 & 15.217 & 2.301 & 5.252 & 1.593 & 2.619 & 3.869 \\
\hline $\mathrm{CV}(\%)$ & 111.282 & 199.74 & -266.638 & 36.116 & 95.661 & 7.233 & 32.326 & 26.667 \\
\hline Paired ' $t$ ' Test & 5.607 & 1.039 & 4.261 & 0.335 & 0.047 & 5.702 & 3.045 & 0.390 \\
\hline 'p' Value & $0.005^{\star}$ & $0.358^{\mathrm{NS}}$ & $0.013^{\star \star}$ & $0.755^{\mathrm{NS}}$ & $0.965^{\mathrm{NS}}$ & $0.005^{\star}$ & $0.038^{\star *}$ & $0.716^{\mathrm{NS}}$ \\
\hline
\end{tabular}

Source : Annual reports of the respective companies. Note: ${ }^{\star}$ Sig. at $1 \%$ level; ${ }^{*}$ Sig. at $5 \%$ level; NS-Not Significant. 
It can be perceived from Table 1 that the mean value of the return on total assets during before-merger period was at the highest at 27.535 in case of Abbott India Ltd., followed by $13.330,12.121,8.017,5.799,5.688,5.300$ and 2.064 as registered by IPCA Labs Ltd., Sequent Scientific Ltd., SMS Pharmaceuticals Ltd., Sri Krishna Pharmaceuticals Ltd., Makers Labs Ltd., Aarti Drugs Ltd. and Strides Shasun Ltd. respectively. The co-efficient of variation of the return on total assets during the same period was at the lowest at 7.413 in case of Abbott India Ltd., followed by 9.945, 26.569, $31.107,53.842,72.703,104.205$ and 320.56 as registered by SMS Pharmaceuticals Ltd., IPCA Labs Ltd., Aarti Drugs Ltd., Sri Krishna Pharmaceuticals Ltd., Sequent Scientific Ltd., Makers Labs Ltd. and Strides Shasun Ltd. respectively. Hence, it can be inferred that during the before-merger period, the return on total assets in case of Abbott India Ltd. was the highest and as well consistent, while it was at the lowest and highly volatile in case of Strides Shasun Ltd.

When examined during after-merger period, the mean value of the return on total assets was at the highest at 36.189 in case of Strides Shasun Ltd., followed by 22.031, $14.507,8.102,6.372,5.491,2.329$, and -5.707 as registered by Abbott India Ltd., IPCA Labs Ltd., Aarti Drugs Ltd., Sri Krishna Pharmaceuticals Ltd., Makers Labs Ltd., SMS Pharmaceuticals Ltd. and Sequent Scientific Ltd. respectively. The co-efficient of variation of the return on total assets during the same period was at the lowest at -266.638 in case of Sequent Scientific Ltd., followed by 7.233, 26.667, 32.326, 36.116, 95.661, 111.282 and 199.74 as registered by Abbott India Ltd., IPCA Labs Ltd., Aarti Drugs Ltd., Sri Krishna Pharmaceuticals Ltd., Makers Labs Ltd., SMS Pharmaceuticals Ltd. and Strides Shasun Ltd. respectively. Hence, it can be comprehended that the return on total assets in case of Strides Shasun Ltd. was the highest but with highest volatility (Net sales had glided up by $137 \%$ during FY 2015-16 over the preceding year due to a significant surge in the regulated market.), while it was at the lowest with the least volatility in case of Sequent Scientific Ltd.

The result of paired't' test shows that null hypothesis is accepted in case of the companies- Strides Shasun Ltd., Sri Krishna Pharmaceuticals Ltd., Makers Labs Ltd. and IPCA Labs Ltd. and hence there is no significant difference in the return on total assets ratio between before and aftermerger periods. On the other hand, the null hypothesis is rejected in case of the companies- SMS Pharmaceuticals Ltd., Sequent Scientific Ltd., Abbott India Ltd. and Aarti Drugs Ltd. and therefore there is a significant difference in the return on total assets ratio between before and aftermerger periods.

\subsection{Return on Capital Employed}

The return on capital employed (ROCE) ratio shows the earning power of the capital invested in the business. It indicates how the management has used the funds supplied by creditors and owners. The higher the ratio, the more efficient is the enterprise in using funds entrusted to it. In order to determine the impact of M\&A on the return on capital employed in respect of the select pharmaceutical companies, the following null hypothesis was framed.

$\mathbf{H}_{0}$ : here is no significant difference in the return on capital employed ratio between before and after-merger periods in respect of the select companies.

Table 2 shows that the mean value of return on capital employed during before-merger period was at the highest at 0.497 in case of Abbott India Ltd., followed by $0.167,0.157,0.118,0.098,0.053,0.008$ and -0.019 as registered by Sequent Scientific Ltd., IPCA Labs Ltd., SMS Pharmaceuticals Ltd., Makers Labs Ltd., Aarti Drugs Ltd., Strides Shasun Ltd., and Sri Krishna Pharmaceuticals Ltd. respectively. The co-efficient of variation of the return on capital employed during the same period was at the lowest at -144.941 in case of Sri Krishna Pharmaceuticals Ltd., followed by $13.665,16.367,33.853,70.863,88.768$, 112.291 and 1004.62 as registered by SMS Pharmaceuticals Ltd., Abbott India Ltd., IPCA Labs Ltd., Aarti Drugs Ltd., Sequent Scientific Ltd., Makers Labs Ltd. and Strides Shasun Ltd. respectively. Hence, it can be construed that during before-merger period the return on capital employed in case of Abbott India Ltd., was the highest with mild volatility, while it was consistently at the lowest with negative return in case of Sri Krishna Pharmaceuticals Ltd.

When observed during after-merger period the mean value of the return on capital employed was at the highest at 0.522 in case of Strides Shasun Ltd., followed by $0.413,0.182,0.091,0.063,0.002,0.001$ and -0.181 as registered by Abbott India Ltd., IPCA Labs Ltd., Aarti Drugs Ltd., Makers Labs Ltd., Sri Krishna Pharmaceuticals Ltd., SMS Pharmaceuticals Ltd. and Sequent Scientific Ltd. respectively. The co-efficient of variation of the return on capital employed during the same period was at the lowest at -147.509 in case of Sequent Scientific Ltd., followed by $7.752,37.193,57.048,155.027,204.86,913.895$ and 2789.89 as registered by Abbott India Ltd., IPCA Labs Ltd., Aarti Drugs Ltd., Makers Labs Ltd., Strides Shasun Ltd., Sri Krishna Pharmaceuticals Ltd. and SMS Pharmaceuticals Ltd. respectively. Hence, it can be perceived that during after-merger period, the return on capital employed in case of Strides Shasun Ltd. was the highest with higher volatility, while it was consistently at the lowest with negative return in case of Sequent Scientific Ltd. 
Table 2: Return on Capital Employed Ratio (In Times)

\begin{tabular}{|c|c|c|c|c|c|c|c|c|}
\hline Period & $\begin{array}{c}\text { SMS } \\
\text { Pharmaceuticals } \\
\text { Ltd. }\end{array}$ & $\begin{array}{c}\text { Strides } \\
\text { Shasun } \\
\text { Ltd. }\end{array}$ & $\begin{array}{l}\text { Sequent } \\
\text { Scientific } \\
\text { Ltd. }\end{array}$ & $\begin{array}{c}\text { Sri Krishna } \\
\text { Pharmaceuticals } \\
\text { Ltd. }\end{array}$ & $\begin{array}{c}\text { Makers } \\
\text { Labs Ltd. }\end{array}$ & $\begin{array}{l}\text { Abbott } \\
\text { India } \\
\text { Ltd. }\end{array}$ & $\begin{array}{c}\text { Aarti } \\
\text { Drugs } \\
\text { Ltd. }\end{array}$ & $\begin{array}{l}\text { IPCA } \\
\text { Labs. } \\
\text { Ltd. }\end{array}$ \\
\hline \multirow{5}{*}{ Before Merger } & 0.14 & 0.07 & 0.22 & -0.04 & -0.01 & 0.46 & 0.03 & 0.12 \\
\hline & 0.11 & 0.06 & 0.33 & -0.03 & 0.07 & 0.40 & 0.03 & 0.21 \\
\hline & 0.10 & 0.05 & 0.26 & -0.04 & 0.01 & 0.50 & 0.03 & 0.18 \\
\hline & 0.13 & -0.13 & 0.01 & 0.01 & 0.22 & 0.62 & 0.05 & 0.08 \\
\hline & 0.11 & -0.01 & 0.01 & 0.01 & 0.20 & 0.51 & 0.12 & 0.20 \\
\hline Mean & 0.118 & 0.008 & 0.167 & -0.019 & 0.098 & 0.497 & 0.053 & 0.157 \\
\hline SD & 0.016 & 0.084 & 0.148 & 0.028 & 0.110 & 0.081 & 0.038 & 0.053 \\
\hline CV (\%) & 13.665 & 1004.62 & 88.768 & -144.941 & 112.291 & 16.367 & 70.863 & 33.853 \\
\hline \multirow{5}{*}{ After Merger } & 0.01 & 0.05 & 0.09 & 0.01 & 0.16 & 0.40 & 0.05 & 0.20 \\
\hline & -0.02 & 0.03 & 0.02 & -0.03 & -0.08 & 0.42 & 0.02 & 0.20 \\
\hline & -0.01 & 0.07 & -0.11 & 0.02 & 0.13 & 0.37 & 0.11 & 0.20 \\
\hline & -0.04 & 0.02 & -0.38 & 0.01 & 0.01 & 0.42 & 0.14 & 0.24 \\
\hline & 0.06 & 2.43 & -0.53 & 0.01 & 0.09 & 0.46 & 0.13 & 0.07 \\
\hline Mean & 0.001 & 0.522 & -0.181 & 0.002 & 0.063 & 0.413 & 0.091 & 0.182 \\
\hline SD & 0.037 & 1.069 & 0.267 & 0.020 & 0.097 & 0.032 & 0.052 & 0.068 \\
\hline CV (\%) & 2789.89 & 204.86 & -147.509 & 913.895 & 155.027 & 7.752 & 57.048 & 37.193 \\
\hline Paired ' $t$ ' Test & 6.022 & 1.060 & 5.244 & 1.622 & 0.474 & 2.240 & 1.914 & 0.498 \\
\hline 'p' Value & $0.004^{\star}$ & $0.349^{\mathrm{NS}}$ & $0.006^{*}$ & $0.180^{\mathrm{NS}}$ & $0.660^{N S}$ & $0.089^{N S}$ & $0.128^{\mathrm{NS}}$ & $0.645^{\mathrm{NS}}$ \\
\hline
\end{tabular}

Source: Annual Reports of the respected companies. Note: ${ }^{\star}$ Sig. at $1 \%$ level; ${ }^{\star \star}$ Sig. at $5 \%$ level; NS- Not Significant

The result of paired ' $\mathrm{t}$ ' test shows that the null hypothesis holds good in case of six out of eight companies with the exception of SMS Pharmaceuticals Ltd. and Sequent Scientific Ltd. Hence, it is concluded that there is no significant difference in the return on capital employed ratio between before and after-merger periods of the six out of eight select companies namely, Strides Shasun Ltd., Sri Krishna Pharmaceuticals Ltd., Makers Labs Ltd., Abbott India Ltd., Aarti Drugs Ltd. and IPCA Labs Ltd. On the other hand, there is a significant difference in the return on capital employed ratio between before and aftermerger periods of the two remaining companies- SMS Pharmaceuticals Ltd. and Sequent Scientific Ltd.

\section{Key Findings}

\subsection{Impact on Profitability- ROTA}

- During before-merger period, the return on total assets in case of Abbott India Ltd. was the highest and as well consistent (Mean 27.535 with CV 7.413\%), while it was at the lowest and highly volatile in case of Strides Shasun Ltd. (Mean 2.064 with CV 320.56\%).

- During after-merger period, the return on total assets in case of Strides Shasun Ltd. was the highest with the highest volatility (Mean 36.189 with CV 199.74\%), while the same for Sequent Scientific Ltd. was negative and the lowest with the least volatility (Mean -5.707 withCV -266.638\%)..

- According to paired ' $\mathrm{t}$ ' test, there is a significant difference in the return on total assets ratio between before and after-merger periods for SMS Pharmaceuticals Ltd., Sequent Scientific Ltd., Abbott India Ltd. and Aarti Drugs Ltd. as the null hypothesis is rejected, while there is no significant difference in case of the remaining four companies..

\subsection{Impact on Profitability- ROCE}

- During before-merger period, the return on capital employed in case of Abbott India Ltd., was the highest with mild volatility (Mean 0.497 with CV $16.367 \%$ ), 
while it was consistently negative and the lowest in case of Sri Krishna Pharmaceuticals Ltd.(Mean-0.019 with CV -144.941\%).

- During after-merger period, the return on capital employed in case of Strides Shasun Ltd. was the highest with higher volatility (Mean 0.522 with CV 204.86\%), while it was consistently negative and the lowest in case of Sequent Scientific Ltd.(Mean - 0.181 with CV $-147.509 \%)$.

- According to paired ' $t$ ' test, there is a significant difference in the return on capital employed ratio between before and after-merger periods for two of the select companies only namely, SMS Pharmaceuticals Ltd. and Sequent Scientific Ltd. as the null hypothesis is rejected, while there is no significant difference in case of the remaining six companies.

\section{Conclusion}

The analysis of the impact of M\&A on profitability of the eight select Indian pharmaceutical companies has divulged that in case of SMS Pharmaceuticals Ltd. and Sequent Scientific Ltd., there was a significant difference in terms of both ROTA and ROCE between before-merger and aftermerger periods (Ho rejected), while in case of Abbott India Ltd. and Aarti Drugs Ltd. there was a significant difference in terms of ROTA alone between before-merger and aftermerger periods (Ho rejected). Hence this analysis confirms the need to act meticulously by the select Indian pharma- ceutical companies to increase their profitability position in future, i.e. after merger.

\section{References}

1. Available from: https://www.ibef.org/industry/pharmaceutical-india.aspx

2. Available from: https://www.yesbank.in/pdf/the_indian pharmaceutical_industry_changing_dynamics.pdf

3. Higgins MJ, Rodriguez D. The outsourcing of $R \& D$ through acquisitions in the pharmaceutical Industry. Georgia State University,Emory University; 2005. 1-47.

4. Grill P, Bresser RKF. Resource-based Theory and Mergers and Acquisitions success. School of economics; 2011. $1-11$.

5. Teixeira N. Mergers and Acquisitions: The case of Merck and $\mathrm{Co}$ and Schering-Plough Corporation. School of Business and Economics; 2012. 1-98.

6. Zhu PC, Hilsenrath PE. Mergers and Acquisitions in U. S. Retail Pharmacy. Journal of Health Care Finance; 2014. $1-20$.

7. Duggal N. Post Merger Performance of Acquiring Firms: A Case Study on management and Business Studies. 2015; 2(3):24-8.

8. Chaudary S, Sarwar A. Returns to shareholders in Acquisitions into the U. S. Pharmaceutical Companies. International Journal of Health and Economic Development. 2015; 1(2):14-27.

9. Santosh Kumar Sahu, Nitika Agarwal. Mergers and Acquisitions in the Indian Pharmaceutical Sector.Madras School of Economics; 2015. 1-34. 